\title{
Correction to: Complete plastid genome of Kappaphycus alvarezii: insights of large-scale rearrangements among Florideophyceae plastid genomes
}

\author{
Na Liu ${ }^{1,2,3} \cdot$ Lei Zhang $^{1} \cdot$ Xianming Tang ${ }^{4} \cdot$ Xumin Wang $^{5} \cdot$ Maria Dyah Nur Meinita $^{6,7} \cdot$ Guoliang Wang $^{5} \cdot$ \\ Weizhou Chen $^{8} \cdot$ Tao Liu $^{1}$
}

Published online: 4 November 2019

(C) Springer Nature B.V. 2019

\section{Correction to: Journal of Applied Phycology}

https://doi.org/10.1007/s10811-019-01815-8

The original version of this article unfortunately contained a mistake. An asterisk was missing in Fig. 4. The correct image of Fig. 4 is now shown here:

The online version of the original article can be found at https://doi.org/ 10.1007/s10811-019-01815-8

Tao Liu

liutao@ouc.edu.cn

1 College of Marine Life Sciences, Ocean University of China, Qingdao 266100, China

2 College of Life Sciences, Beijing Normal University, Beijing 100875, China

3 National Institute of Biological Sciences, Beijing, Beijing 102206, China

4 Hainan Academy of Ocean and Fisheries Sciences, Haikou 570203, China
CAS Key Laboratory of Genome Sciences and Information, Beijing Key Laboratory of Genome and Precision Medicine Technologies, Beijing Institute of Genomics, Chinese Academy of Sciences, Beijing 100101, China

6 Center for Maritime Biosciences Studies, Institute for Research and Community Service, Jenderal Soedirman University, Purwokerto 999006, Indonesia

7 Faculty of Fisheries and Marine Science, Jenderal Soedirman University, Purwokerto 999006, Indonesia

8 Marine Biology Institute, Shantou University, Shantou 515063, China 

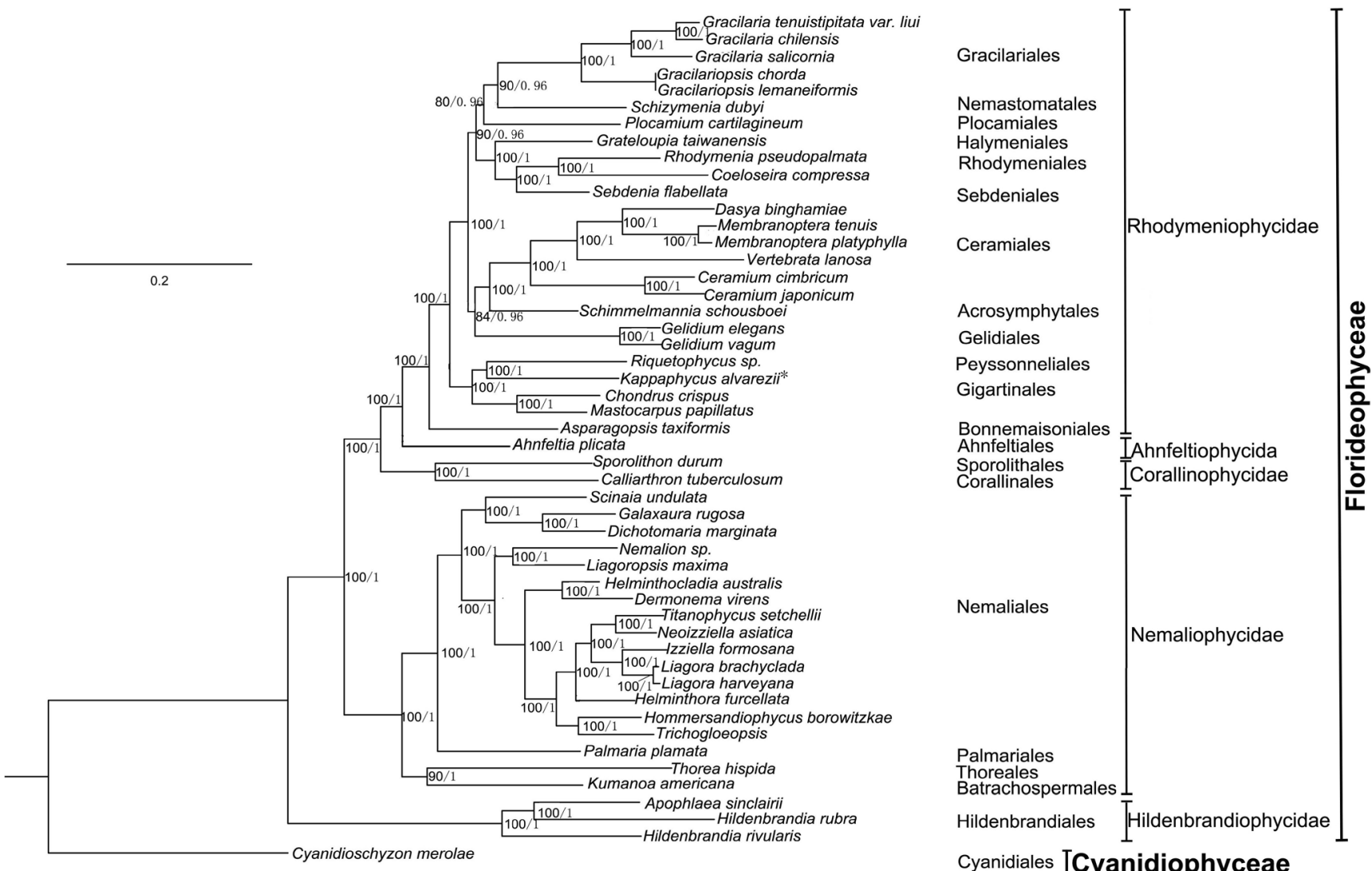

Cyanidiales ICyanidiophyceae

Fig. $4 \mathrm{ML}$ and BI phylogenetic trees generated using 144 concatenated plastid protein-coding genes from 49 Florideophyceae species. Cyanidioschyzon merolae was set as an outgroup; the support values for each node are shown from maximum likelihood bootstrap and Bayesian posterior probabilities. Asterisk indicates newly sequenced Kappaphycus alvarezii in this study

Publisher's note Springer Nature remains neutral with regard to jurisdictional claims in published maps and institutional affiliations. 